ALPHA Nº 28 Julio 2009 (245-256)

ISSN 0716-4254

http://alpha.ulagos.cl

\title{
LA POLÍTICA EN LA HORA DEL LOBO DEL HOMBRE: PROPUESTA PARA UNA LECTURA ARENDTIANA DE LA TEORÍA DEL CONTRATO SOCIAL DE HOBBES
}

Politics in the time of the Wolfman: An Arendtian reading of Hobbes' Social

Contract

Claudia Fuentes*

Resumen

A pesar de las profundas diferencias que separan las concepciones de lo político de Arendt y Hobbes, la autora nos sorprende con el reconocimiento de un acuerdo fundamental entre ambos: "La política surge en el entre y se establece como relación. Así lo entendió Hobbes”. ¿Cómo dotar de contenido este aparente entendimiento entre Arendt y Hobbes? ¿Qué elementos de la teoría política del segundo pueden sostener el reconocimiento de la primera y ser pensados desde su concepto de lo político? El presente artículo surge de estas preguntas, y propone una lectura del contrato social de Hobbes en la que el momento mismo del pacto es interpretado como la fugaz aparición de la acción política arendtiana.

Palabras clave: Arendt, Hobbes, contrato social, pluralidad, acción.

Abstract

Despite the profound differences separating Arendt and Hobbes' political ideas, Arendt offers a surprising acknowledgement of the fundamental underlying agreement between the two: "Politics emerges from the in-between space and becomes a relation. This is how Hobbes understood it". How can we make sense of this apparent concurrence? What elements of Hobbes' political theory support Arendt's recognition and can be viewed through her concept of the political? From this starting point, the article proposes a reading of Hobbes' social contract in which the pact is interpreted as momentary appearance of arendtian political action.

Key words: Arendt, Hobbes, social contract, pluralism, action.

Thomas Hobbes es, en muchos sentidos, el modelo del filósofo moderno a quien se opone la teoría política de Hannah Arendt. Su descripción de la condición natural del hombre como una guerra de todos contra todos motivada por la competencia, la desconfianza y el afán de gloria; la supresión de esta guerra como fundamento y sentido del contrato social que da origen al Soberano Leviatán; la identificación de la política con el monopolio del poder que los pactantes ceden a este Soberano a cambio de seguridad ( $C$ fr. Hobbes, 


\section{Claudia Fuentes}

2003:100-131) y su concepción de la libertad como ausencia de impedimentos externos que la sitúan en una dimensión individual y extrapolítica, transformando en mera ingenuidad la pretendida libertad republicana de los ciudadanos de Luca ${ }^{1}$ son todos elementos del prejuicio moderno que según Arendt han impedido a la filosofía pensar la política, y sobre cuya oposición construye esta autora las líneas centrales de su pensamiento (2005:89-99). ${ }^{2}$

A la guerra natural de todos contra todos, concebida según Arendt desde una visión uniformadora del hombre que hace superflua la existencia de copias idénticas de una naturaleza humana universal (2005:47), ${ }^{3}$ la autora opone la idea de la pluralidad como la unicidad original de cada cual que se expresa en la esfera pública y es condición de esta esfera (1993:200-205). Al Leviatán interpretado por Arendt desde la lógica medio fin de la fabricación (1993:325) que ve al espacio público como un objeto de construcción, y reduce a la política a instrumento de la seguridad privada (330-338) ${ }^{4}$ - la autora opone su concepción de la política como acción — praxis y lexis - cuyo contenido es la libertad que hace posible el surgimiento de lo inaudito y de la que no cabe esperar resultados predecibles (1993:200 y ss). A la identificación del poder con el monopolio de la violencia (2004:206), Arendt opone una visión del poder como la acción concertada de la pluralidad que nunca puede ser ejercida por un sujeto particular (1993:263). Por último, a la libertad individual y extrapolítica de Hobbes, la autora opone su concepción de la libertad como la capacidad para iniciar procesos nuevos, libertad en la que consiste la política $(1996: 173 \text { y ss })^{5}$

\footnotetext{
${ }^{1}$ Thomas Hobbes. Leviatán. Argentina: F. C. E., 2003:175. Citaremos por esta edición. Destaco este ejemplo en atención a la tesis de Q. Skinner, según la cual, Hobbes habría elaborado su teoría política - especialmente su concepto de libertad- como respuesta a la teoría del republicanismo (2005:4-7).

2 Étienne Tassin ha resumido estos prejuicios en tres ideas centrales que, perfectamente, podrían considerarse los tres supuestos de la obra política de Hobbes: “1. El recurso a un modo de pensamiento instrumental o teleológico, que nos hace adoptar la categoría medios-fines para interpretar la política como si ella estuviera al servicio de una finalidad exterior a sí misma; 2 . La asimilación del contenido de la política con la violencia como medio de alcanzar ese fin; 3. La idea de dominación como concepto central de la teoría política” (2007:106).

3 "Naturaleza" elaborada, según Arendt, a partir de las necesidades de la naciente sociedad burguesa, “...cuya creencia fundamental en un inacabable proceso de acumulación de propiedad estaba a punto de eliminar toda la seguridad individual” (2004:203).

${ }^{4}$ Para Arendt, la identificación política-seguridad operada por Hobbes sería reflejo de la mala opinión que éste tendría de la esencia de la política (1996:162). En este sentido, la lógica medio-fin de la acción política hobbesiana podría incluso considerar a las mentiras como recursos válidos para garantizar el espacio de búsqueda de la verdad (1996:240).

${ }^{5}$ Arendt destaca el carácter marginal de la libertad en la teoría política de Hobbes: “...casi no existe escuela de pensamiento político en nuestra historia que no se centre en la idea de
} 
No resultaría exagerado sostener, entonces — como hace É. Tassin— que Hannah Arendt ha escrito un "Contra Hobbes". Sin embargo, la misma Arendt nos sorprende con el reconocimiento de un acuerdo fundamental entre ella y este autor, en un pasaje del breve Fragmento Uno de ¿Qué es la política?

La filosofía tiene dos buenos motivos para no encontrar nunca el lugar donde surge la política. El primero es: a) Zoon Politikon: como si hubiera en el hombre algo político que perteneciera a su esencia. Pero esto no es así: el hombre es a-político. La política nace en el Entre-los-hombres, por lo tanto completamente fuera del hombre. De ahí que no haya ninguna substancia propiamente política. La política surge en el entre y se establece como relación. Así lo entendió Hobbes (2005:46. El destacado es mío).

Lo que Hobbes parece haber entendido es que el locus específico de lo político no radica nunca en los hombres considerados individualmente: la politicidad no es una dimensión del sujeto particular, sino de la relación que puede llegar a establecer con los demás. Pero ¿Cómo dotar de contenido este aparente “entendimiento" entre Hobbes y Arendt? ¿Qué elementos de la teoría política del primero pueden sostener el reconocimiento de la segunda y ser pensados desde su concepto de lo político?

Trataremos es dar respuesta a estas preguntas, a partir de una lectura que utiliza las categorías políticas arendtianas —acción, igualdad, pluralidad, libertad- para interpretar los elementos de la teoría del contrato social de Hobbes. El supuesto de esta lectura es que hay un momento en el contrato social, precisamente el momento cuando se pacta la formación del Leviatán, en el que los lobos de Hobbes se comportan como los fundadores políticos de Arendt y que sería el momento que ella tiene en mente en la cita señalada. Siguiendo el ejemplo de Arendt, en su prólogo a La condición humana (1993:18) centro mi lectura en lo que los hombres de Hobbes hacen cuando pactan, y no en lo que “aparentemente son”. 6

\footnotetext{
libertad, por mucho que pueda variar el concepto básico... La única excepción de cierta importancia en cuanto a esta afirmación me parece que es la filosofía política de Thomas Hobbes" (1996:07).

${ }^{6}$ Esta distinción resulta inadecuada dentro del pensamiento de Arendt, para quien la esfera política no admite la distinción entre ser-hacer-aparecer: en ella somos como aparecemos actuando (1992:66). Opongo "hacer” y "parecer ser" sólo como recurso para distinguir la descripción del hombre hecha por Hobbes (su aparente naturaleza) y aquello que estos hombres hacen cuando pactan.
} 


\section{Claudia Fuentes}

\section{ESTADO DE NATURALEZA DEL HOMBRE O DE LA CONDICIÓN APOLÍTICA ORIGINAL}

Conviene iniciar esta presentación del Estado de Naturaleza de Hobbes recordando una advertencia que sus comentadores —entre ellos la misma Arendt (1992:19)— suelen hacernos: la condición originaria del hombre descrita por Hobbes no tiene pretensión de verdad histórica. Es una hipótesis lógica, una suerte de "juego de imaginería” que nos sitúa fuera de la polis, en una dimensión pre-política, para considerar, desde allí, los orígenes y fundamentos del poder, en una época cuando el derecho divino de los reyes estaba en entredicho. Se trata, entonces, de un recurso teórico similar al "espacio vacío" —desde el cual Galileo explica el movimiento de los cuerpos- que nos permite, en este caso, arrojar luz desde el no lugar del estado de naturaleza y el contrato social, hacia la situación histórica de la comunidad política.

Desde una perspectiva arendtiana, el modelo contractualista tiene un valor hermenéutico particular, pues, en la escisión imaginaria que nos retrotrae a una condición original fuera de la polis, se hace presente la posibilidad de separar los dos órdenes de vida activa en los que habita el hombre: la dimensión pre-política relacionada con la conservación de la vida y la fabricación y la dimensión política relativa a las cosas en común (1993:21-33). En este momento de escisión, el estadio no político que presenta Hobbes adquiere la forma clásica de lo privado, dominado por la necesidad y la búsqueda de subsistencia que dan origen a la familia por "la natural inclinación de los sexos, entre sí, y respecto a sus hijos” (2003:163). "El rasgo distintivo de la esfera doméstica — nos dirá Arendt refiriéndose al mundo clásico- era que en dicha esfera los hombres vivían juntos llevados por sus necesidades y exigencias" (1993:43).

Pero, además, el estado natural responde a una tesis fundamental de Hobbes en la que centró, coincidiendo con Artendt, su crítica a la teoría política clásica, rechazando la premisa aristotélica del zoon politikon y de la polis como espacio natural para el despliegue de las potencialidades humanas. ( $C f r$. Hobbes, 2000:III cap. XIII; Strauss, 1972:169; Arendt, 2005:46). La hipótesis del estado original pre-político se sostiene en una concepción artificial y contingente de la política y representa, como en la descripción de Arendt de la estructura social previa a la Revolución Norteamericana, la imagen de una "multitud libre de todo lazo y de toda organización política” (1992:187), la llamada "sociedad disuelta" de Hobbes (2000:Prefacio) que funda lo político.

Sin embargo, este estado original es - también para Hobbes - un estado de profunda escasez que impide a los hombres conseguir de la naturaleza todos los bienes que necesitan para vivir. La escasez nos enfrenta a una suerte de juego de suma cero y de muchos participantes, porque todo lo que alguno de 
ellos obtiene de la naturaleza es, también, aquello de lo que priva a los demás. ${ }^{7}$ La consecución de bienes no dependerá, entonces, de las facultades productivas de los hombres, sino de su capacidad para competir — y competir a muertecon otros. Esta competencia trae consigo las desconfianzas mutuas que impelen a los hombres a buscar la sumisión de sus potenciales adversarios mediante la violencia y la astucia, como un recurso fundamental para sobrevivir, porque "si alguien planta, siembra, construye o posee un lugar conveniente, cabe esperar que vengan otros para desposeerle y privarle, no sólo del fruto de su trabajo, sino también de su vida o su libertad” (2003:101).

El estado de naturaleza descrito por Hobbes es un estado de guerra de todos contra todos. En este escenario, la violencia es, a la vez, el recurso prioritario y el máximo peligro para la supervivencia. Con la extensión total de la violencia, la esfera pre-política queda inhabilitada para cumplir su función originaria. La síntesis que hace Hobbes de la condición humana en este estado como una forma de vida "solitaria, pobre, tosca, brutal y breve" (2003:103) nos muestra en su más radical versión el poder deshumanizante de la soledad descrito por Arendt bajo la forma del desarraigo ${ }^{8}$ y de "el hecho de la pobreza" como la permanente sumisión del hombre al imperio de la necesidad.

Desde esta precariedad surgen las tres pasiones que, según Hobbes, mueven al hombre a pactar y que definirán, en gran medida, las condiciones impuestas por la razón al pacto: el temor constante a una muerte violenta en la interpretación de Arendt, "la igualdad del temor ante la capacidad de matar" (1970:61), el deseo de obtener bienes para una vida mejor y la esperanza de lograrlos mediante el trabajo (Cfr. Leviatán, 105).

Arendt coincidirá con Hobbes en su concepción de la violencia como un medio necesario y justificado en la esfera pre-política para "someter a la necesidad" — y en este sentido el dominio ejercido por el pater familias es el mejor ejemplo- y como recurso marginal en la fundación política; pero rechazará, como su consecuencia, la guerra total del estado originario y la necesidad de establecer un poder político que utilice esa misma violencia para aplacar la guerra (1993:42). Del mismo modo, Arendt acepta la dimensión privada y apolítica del reino de la necesidad, pero rechaza su función como origen espurio de la actividad política que contiene el germen corruptor del pacto: la transformación de lo privado en un asunto social. ${ }^{9}$

\footnotetext{
${ }^{7}$ Hobbes representa esta competencia con la imagen de una carrera en la que "debemos suponer que... no tiene otra meta, otro premio, que ser el primero” 1979:9-21.

8 "Estar desarraigado significa no tener en el mundo un lugar reconocido y garantizado por los demás” (2004:56).

${ }^{9}$ Los hombres de Hobbes que no pudieron garantizar su conservación en el estado de naturaleza se han unido para fabricar un Leviatán que proteja la comunidad. De este modo, la
} 


\section{Claudia Fuentes}

Sin embargo, el contrato social que este estado de naturaleza inspira, considerado en sí mismo con un acto fundacional, puede dar cuenta - a mi juicio - del sentido más profundo que Arendt le asigna a la política. A pesar de su defecto de origen, su destino - e incluso de sus cláusulas- encontramos en este acto la fugaz aparición de la acción como tercera dimensión de la vida activa. Conviene, aquí, seguir paso a paso, las características del efímero momento del contrato para intentar dar cuenta de las razones que llevaron a Arendt a afirmar que Hobbes entendió que la política surge "Entre los hombres".

\section{EL CONTRATO SOCIAL COMO ACTO FUNDACIONAL}

Un primer rasgo del contrato social como acto fundacional es la suspensión de la guerra. Si en el estado de naturaleza prima la violencia - aquella fuerza muda que excluye de lo político a la Revolución- en el momento de contratar (tratar con otros) priman la palabra y el acuerdo: se trata de que "uno acceda, si los demás consienten también" (2003:107). En este sentido, aunque la política de Hobbes se juega siempre en los márgenes de la violencia de modo que su supresión momentánea sirve sólo para la “canalización de una violencia” que en adelante se identificará con el poder político (Habermas, 2005:216), el acto mismo de pactar se efectúa al margen de las coerciones recíprocas del estado de naturaleza y del dominio del Leviatán y constituye el común acuerdo de los pactantes para fundar la comunidad política. En este sentido, el acto fundacional de Hobbes cumple con la distinción entre "Violencia” y "Poder”, establecida por Arendt, y sitúa a este último - "la capacidad humana de concertarse con los demás para actuar de común acuerdo" - ${ }^{10}$ como el elemento nuclear de la relación que inaugura lo político.

dimensión privada se hace condición de la vida política en un sentido inverso al seguido por Arendt: mientras para ella la libertad constitutiva de lo político emerge cuando las necesidades cotidianas son satisfechas en el mundo privado, para Hobbes la dimensión política surge como un medio para limitar la libertad natural y establecer la paz como condición de dicha satisfacción.

${ }^{10}$ Habermas ha destacado la implicancia que tiene la distinción operada por Arendt entre violencia y poder para la concepción del derecho, contraponiéndolas precisamente al modelo contractualista del derecho natural. Para este último, el poder-violencia individual al que renuncian los pactantes en favor del monopolio del poder-violencia estatal, es el fundamento del derecho que opera como "disciplinadora imposición de libertades subjetivas restringidas mediante la ley”. Para Arendt, en tanto, la distinción entre violencia y poder le permite vincular al derecho al primero, excluyendo radicalmente al segundo. Así, el poder político es entendido como "fuerza autorizadora que se manifiesta en la creación de derecho legítimo y en la 
Esto nos lleva a un segundo rasgo del acto fundacional: el pacto exige la presencia de otros con quienes pactar. Se trata de un acto fundamentalmente público en la medida en que la "renuncia al derecho a todas las cosas" sólo es tal en la presencia de los otros que también renuncian y se transforman en actores y testigos del pacto. Lo que se publica en este caso, como señala Strauss, no es la grandeza de los pactantes deseosos de gloria, sino el privado y vergonzoso reconocimiento del temor a la muerte ${ }^{11}$ que "en tanto enemigo común, los fuerza a un mutuo entendimiento, confianza y unión, y les procura entonces la posibilidad de culminar en la fundación del Estado” (2006:47).

En este acto de renuncia, los pactantes se sitúan en una posición de igualdad porque todos se presentan como señores — señores con "derecho a todas las cosas" y que temen morir- entre los que no cuentan las relaciones de subordinación: el requisito para pactar la sumisión a un tercero es estar libre del dominio de otro al momento de pactar. Éste es, precisamente, el tipo de igualdad que busca sostener Hobbes en su descripción de la igualdad física del hombre natural: derivada del hecho de que todos podemos morir y matar, reduce las condiciones de dominación originadas por las desconfianzas mutuas, no sólo a situaciones de hecho sino, también, a situaciones revocables que obligan al dominador natural a pactar con todos los demás como si no existiera dominación. En este sentido, si bien la igualdad descrita por Hobbes responde a un "factor igualador" que Arendt rechaza para la esfera política - esto, porque la muerte como "factor igualador" nos reduciría a la uniformidad biológica, (1993:236) - el tipo de igualdad que este factor sostiene, la igualdad en la no dominación, coincide con la igualdad exigida según Arendt por la esfera política: el encuentro de pares entre los que no existen gobernantes ni gobernados (1993:44-45).

A partir de esta separación entre la muerte como factor igualador y su resultado en la igualdad como no subordinación, los pactantes de Hobbes podrían sortear el requisito de la distinción — precisamente, la ausencia de una "medida o denominador común"- exigido por el concepto de pluralidad de Arendt. La pluralidad entendida como "la simultánea presencia de innumerables perspectivas y aspectos en los que se presenta el mundo común" (1993:200) es para Arendt la condición básica de la política y uno de los

fundación de instituciones” (2005:215-216). Coincidiendo con esta oposición entre Arendt y Hobbes, oposición que, por lo demás, destaca ella misma (1996:28), creo que es posible sostener que en el momento del pacto - y sólo en ese momento- cuando se suprime la violencia, nos encontramos con la forma pura del poder concertado fundador del que habla Arendt.

${ }^{11}$ Recordemos que Leviatán es también "el rey de los orgullosos” que menosprecia todas las cosas altas y es rey de todas las criaturas soberbias (2003:262). 


\section{Claudia Fuentes}

aspectos más discutibles a la hora de intentar interpretar el pacto social como un acto fundacional arendtiano. En efecto, el hecho de que este pacto inspirado por el temor a la propia muerte se realice desde el más absoluto egoísmo natural, parece situarnos en una dimensión radicalmente subjetiva que limita cualquier intento por pensar la pluralidad: si el hombre es como Hobbes afirma - ha dicho Arendt - la "pertenencia a cualquier tipo de comunidad es... un asunto temporal y limitado que esencialmente no cambia el carácter solitario y privado del individuo" (2004:200). ${ }^{12}$

Atendiendo a este punto, Habermas incluso ha llegado a negar la posibilidad misma del pacto porque, atrapados en un "egoísmo de perspectivas” (2005:426) los lobos de Hobbes no estarían en condiciones de adoptar y adoptarse desde la perspectiva de los demás y, menos aún, imaginar la perspectiva plural del beneficio compartido que supone el pacto (2005:156-157).

¿En qué sentido, entonces, podrían estos hombres de "juicio degradado" cuyas opiniones actúan como "sirvientes calculadores" del egoísmo (Denneny, 1994:95) vivir una pluralidad que hiciera posible la relación política que Arendt les atribuye ${ }^{13}$ Ciertamente, no podría tratarse del tipo de pluralidad en el que la diversidad de perspectivas se expresa — como sostiene Diego Paredes recordando a Arendt - en el "intercambio público donde se hace posible discutir asuntos como qué es lo bueno, lo malo, lo justo, lo injusto” (2007:181). Pero si este tipo de intercambio no es posible, al menos, es necesario el intercambio público de la renuncia en el que cada uno se presenta ante los otros como el portador de una perspectiva singular que puede negarse a pactar y de cuyo discurso de renuncia unido al discurso de los demás se nutre el contrato social. Tal es el tipo de pluralidad que hace posible la democracia que precede

\footnotetext{
12 En esto parece estar pensando Vallespín al señalar que "El contrato tampoco puede entenderse como el resultado de un previo proceso de comunicación intersubjetiva” sino como, "la decisión última de estrictos preferidores racionales guiados exclusivamente por su propio interés, no guiados por un fin colectivo” (2006:132).

${ }^{13}$ Recordemos las palabras que inspiran nuestra lectura: "La política surge en el entre y se establece como relación. Así lo entendió Hobbes”. Creo que la pluralidad es el supuesto del reconocimiento de Arendt, para quien la relación política solo es posible en la condición de pluralidad. En este sentido, es esclarecedora la lectura que hace Miguel Vatter de las palabras de Arendt: "Aristotle, like the western political tradition after him up to but not including Hobbes, according to Arendt, misses the basic distinction between "Man" and "men", between human nature and The human Condition of plurality. It is this plurality of men that first makes possible the in-between of politics, and therefore the in-between cannot possibly be reduced to the bios politikos of man, as Aristotle wants to do". "“Aristóteles como la tradición política occidental posterior a él a excepción de Hobbes, olvidó la distinction básica entre "El Hombre" y los hombres; entre la naturaleza humana y La condición humana de la pluralidad. Es esta pluralidad de los hombres la que hace possible en "en- entre" de la política, y por lo tanto no puede ser reducida a bios politikos, como pretende Aristóteles” (2006:147). Traducción nuestra.
} 
a todo gobierno (Hobbes, 2002:III, cap 2), el tipo de pluralidad a partir de la cual cobra sentido la ley del Evangelio, que Hobbes nos recuerda al momento de pactar, y en la que "la perspectiva del otro" forma parte de la propia deliberación: "Lo que pretendáis que los demás os hagan a vosotros, hacedlo vosotros a ellos” (2003:107). Pero es, también, el tipo de pluralidad que temerosa de la guerra que ella misma origina pacta su propia supresión y le concede al Leviatán la función de imponer una sola perspectiva desde la cual se gobierna toda opinión (146).

De este modo, si bien la concepción uniformadora del hombre que explica la guerra de todos contra todos hace de ellos figuras del "qué" propias de la esfera del trabajo descrita por Arendt, la presencia del otro igual y diverso en el momento del pacto es la presencia de un "quien" que se muestra a los demás como un individuo cuya palabra de renuncia es irreductible a la renuncia de los demás. En el momento del pacto parece haber operado un cambio fundamental en la manera como el otro aparece frente a aquél con quien pacta. Si en el estado de naturaleza se presentaba como "lo otro" objeto de dominación - recordemos que el derecho a todas las cosas incluye el derecho a la vida y al cuerpo de los demás - en el momento de pactar, el "otro" se presenta como otro señor con igual derecho natural y cuyo pacto efectivo es el requisito necesario para el pacto de los demás. ${ }^{14}$

Esta idea se ve reforzada en el reconocimiento del pacto tácito que realizarían "quienes" han nacido en una comunidad ya establecida. Resulta interesante comparar este pacto individual y tácito con el pacto original público en el que la promesa de la renuncia es vista y oída por los demás. El pacto individual es un acto privado, invisible: aceptar la protección del Leviatán es la forma de pactar. El pacto tácito simboliza la ausencia de un espacio público donde pactar y la ausencia de igualdad en tanto, en este caso la renuncia, es equivalente al hecho de la subordinación. Pero el reconocimiento general del derecho a pactar de los nuevos ciudadanos, el hecho de que en cada uno de ellos deba renovarse la fundación original, simboliza, también, el reconocimiento de la novedad que cada uno porta y la posibilidad de desconocer el

\footnotetext{
${ }^{14}$ También podríamos pensar que el pacto social de Hobbes responde mejor a la esfera pública del trabajo definido por aquello que se busca fabricar — en este caso el Leviatán- en el que los pactantes se presentan más como productores que como seres humanos (Arendt, 1993:232; Paredes, 2007:177-178). Una lectura de este tipo sería coherente con la lógica de la fabricación que Arendt le atribuye al pensamiento de Hobbes. Sin embargo, creo que esta opción no debe ser entendida como una refutación de la lectura que propongo en este artículo, sino como la confirmación del supuesto en el que ella se realiza: el contrato social como la fugaz aparición de lo político que porta, en sí mismo, su origen espurio y su germen corruptor.
} 


\section{Claudia Fuentes}

pacto y empezar algo nuevo. ${ }^{15}$ Para Hobbes, el Leviatán — que todo lo puedeno puede fundamentar su propio poder; incluso, cuando su dominio ya se ha establecido necesita de la "aceptación” de los nuevos ciudadanos súbditos, aunque sea en la forma precaria de aceptar la protección.

Esto lleva a la idea central del contrato social interpretado como acto fundacional: el poder del Leviatán no encuentra su fuente de legitimidad en principios “absolutos, trascendentes y trans-humanos" (Arendt, 1992:228). Sino en la promesa misma de sumisión que se hacen mutuamente los pactantes en el acto de pactar. Los lobos de Hobbes podrían, como los revolucionarios de Arendt, arrogarse la calificación de fundadores porque de ellos deriva el poder y porque son conscientes de esta derivación. ${ }^{16}$

Hobbes, como Arendt, entendió el carácter contingente e impredecible de la "acción política". Entendió — como bien grafica Manuel Cruz- que el acontecimiento no es - porque no puede ser - un lugar para quedarse a vivir (2006:94). Pero, a diferencia de Arendt, no estuvo dispuesto a confiar en la promesa como facultad capaz de contener la indeterminación. Para Cruz, la posibilidad de "cumplir lo pactado" — como reza la tercera ley natural que da origen al Leviatán (2006:118) — no puede dejarse a los hombres mismos porque "el que puede sujetar, puede liberar; y por lo tanto, el que sólo está sujeto a sí mismo, no está sujeto a nada” (2006:141). Por eso, los fundadores de Hobbes son sacrificados por el bien del hombre, y entonces —según Arendt- la política es "sólo un medio destinado a proteger a la sociedad" (1993:43).

\footnotetext{
${ }^{15}$ Como los neonatos de Arendt, los nuevos súbditos de Hobbes que confirman con su silencio el pacto, confirman también el "hecho de que el mundo se renueva a diario mediante el nacimiento y que a través de la espontaneidad del recién llegado, (el futuro) se ve arrastrado a algo imprevisiblemente nuevo" (2005:22). Pero por temor a este futuro imprevisible, Hobbes ha preferido reservarles el derecho al silencio, haciendo del mundo un lugar determinado y predecible.

${ }^{16}$ Arendt ha dicho de estos revolucionarios que "sabían muy bien que lo que, andando en el tiempo, se convertiría en fuente de la autoridad del nuevo poder político iba a ser más el propio acto de fundación que un legislador inmortal o una verdad evidente por sí mismo cualquier otra fuente transcendente y transhumana” (1992:228). Si bien los pactantes son la fuente de autoridad del Leviatán, y en este sentido los hemos presentado como fundadores, nuevamente nos enfrentamos al problema de los límites en la aplicación de las categorías arendtianas a la teoría de Hobbes. La fundación, como nos recuerda Espósito a propósito del análisis de Arendt sobre las revoluciones, implica la "ulterioridad", la "proyección constructiva” de un espacio permanente para la libertad (Espósito, 1994:226). El contrato social como acto fundacional garantiza la proyección de una nueva vida en común, pero a costa de suprimir la libertad política.
} 


\title{
CONCLUSIÓN
}

El contrato social, interpretado como acto fundacional, lleva consigo la doble marca de la necesidad y de la utilidad propia del mundo que Arendt sitúa fuera de la esfera política (labor y trabajo); y del comienzo de lo nuevo, propio de su concepción del acontecimiento político. En efecto, según expusi-mos, la necesidad de salvar la vida es la pasión que mueve a la razón a pactar para crear un poder soberano que garantice la seguridad de cada cual, y está en la base de la concepción moderna del Estado Máquina, que Arendt rechaza a lo largo de su obra. Sin embargo, como he intentado mostrar aquí, el contrato social de Hobbes se presenta también como el "golpe de audacia" con el que los hombres reunidos revocan su condición natural para instaurar lo inaudito: la comunidad de los lobos que pactan la paz. En este sentido, el pacto inaugural -interpretado desde las categorías arendtianas de igualdad, pluralidad y liberad - marca el surgimiento de una segunda vida, la vida política. Este sería el descubrimiento de Hobbes que Arendt reconoce en la cita sobre la que se basa mi lectura.

Sin embargo, como se ha hecho patente a lo largo de esa interpretación, se trata de una vida política atrapada en el momento fundacional que se establece para su propia supresión. Lo que los hombres de Hobbes pactan desde la igualdad, la pluralidad y la libertad es, precisamente, la renuncia a la igualdad, la libertad y la seguridad. Arendt y Hobbes pueden haber coincidido al encontrar "el lugar donde surge la política" pero, ciertamente, contaron historias muy distintas respecto del lugar donde debía terminar.

\author{
Universidad Diego Portales* \\ Facultad de Ciencias Sociales e Historia \\ Ejército 333, Santiago (Chile) \\ claudia.fuentes@udp.cl
}

\section{BIBLIOGRAFÍA}

ARENDT, Hannah. ¿Qué es Política? Buenos Aires: Paidós, 2005.

------ Los orígenes del Totalitarismo. Madrid: Taurus, 2004.

------ “¿Qué es la libertad?”, en Entre el Pasado y el Futuro. Barcelona: Península, 1996.

------ La Condición Humana. Barcelona: Paidós, 1993.

------ Sobre la Revolución. Barcelona: Alianza, 1992.

------- Sobre la Violencia. México: Joaquín Mortiz, 1970.

CRUZ, Manuel. “Memoria: extrañeza o reconciliación”, en El Siglo de Hannah Arendt. Barcelona: Paidós, 2006. 
DENNENY, Michael. "El Privilegio de nosotros mismos: Hannah Arendt y el juicio”, en El resplandor de lo público (Claudia Hilb, compiladora). Venezuela: Nueva Sociedad, 1994.

ESPÓSITO, Roberto. "Hannah Arendt entre voluntad y representación”, en El resplandor de lo público (Claudia Hilb compiladora). Venezuela: Nueva Sociedad, 1994.

HABERMAS, Jurgen. Facticidad y Validez. Madrid: Trotta, 2005.

HOBBES, Thomas. Leviatán. Argentina: F. C. E., 2003.

------ De Cive: elementos filosóficos sobre el ciudadano. Madrid: Alianza, 2000.

------- Elementos de Derecho Natural y Político. Madrid: Centro de Estudios Constitucionales, 1979.

PAREDES, Diego. "Pensar la Pluralidad", en Hannah Arendt: Pensadora en tiempos de oscuridad. Número especial de Revista Al Margen, $\mathrm{N}^{\circ} 21 \mathrm{y}$ 22. (marzo-junio 2007):174-181.

SKINNER, Quentin. "El tercer concepto de libertad”, en Revista Claves de Razón Práctica. Madrid (2005):4-8.

STRAUSS, Leo. La filosofía política de Hobbes. Buenos Aires: F. C. E., 2006.

------ Natural Right and History. Chicago: University of Chicago Press, 1972.

TASSIN, Étienne. "El pueblo no quiere", en Hannah Arendt: Pensadora en tiempos de oscuridad. Número especial de Revista Al Margen, $\mathrm{N}^{\circ} 21 \mathrm{y}$ 22. (marzo-junio 2007):106-113.

VALLESPÍN, Fernando. "Hannah Arendt y el Republicanismo”, en El siglo de Hannah Arendt. (Manuel Cruz, Compilador). Barcelona: Paidós, 2006.

VATTER, Miguel. "Natality and biopolitics in Hannah Arendt", en Revista Ciencias Políticas, vol. 26, N² 2. Santiago (2006):137-159.

[online].2006,vol.26,no.2<http://www.scielo.cl/scielo.php?script=sci_artt ext\&pid=S0718-090X2006000200008\&lng=es\&nrm=iso>. ISSN 0718090X. 